\title{
Oxidative coupling of activated alkynes with palladium $(0)$ olefin complexes: Side production of the highly symmetric hexamethyl mellitate species under mild conditions at low alkyne/complex molar ratios
}

\author{
Luciano Canovese *, Fabiano Visentin, Gavino Chessa, Claudio Santo, \\ Carlo Levi, Paolo Uguagliati \\ Dipartimento di Chimica, Università Ca' Foscari, Calle Larga S. Marta 2137, I-31123 Venezia, Italy
}

Received 15 November 2005; accepted 11 January 2006

Available online 9 March 2006

\begin{abstract}
The reactions of oxidative coupling of dimethylacetylene dicarboxylate (DMA) with palladium (0) olefin complexes bearing a pyridylthioether as ancillary ligand give rise to the corresponding palladacyclopentadienyl complexes as the main product and in some cases to the highly symmetric hexamethyl mellitate molecule, especially when a low alkyne(DMA)/complex ratio is employed. A plausible mechanism based on several pieces of experimental evidence is proposed, and the most effective complexes promoting the hexamethyl mellitate synthesis were identified.
\end{abstract}

(C) 2006 Elsevier B.V. All rights reserved.

Keywords: Hexamethyl mellitate; Oxidative coupling; $\operatorname{Pd}(0)$ and $\mathrm{Pd}(\mathrm{II})$ pyridylthioether complexes; Activated alkynes

We have recently studied the mechanism of the attack of substituted alkynes on pyridylthioether olefin palladium $(0)$ complexes leading to the formation of pyridylthioether palladacyclopentadiene derivatives; the reaction studied and the species involved are reported in Scheme 1 [1].

It was soon apparent that the majority of the reactions studied under spectrophotometric conditions ([alkyne]/ $[$ complex $] \geqslant 50$ ) proceeded smoothly to the formation of the palladacyclopentadienyl complexes. In the case of the complex bearing the hindered ancillary ligand $\mathrm{MeN}-\mathrm{S} t \mathrm{Bu}$ however, the reaction path was markedly complicated by the accumulation of a scarcely reactive intermediate which was identified as the monoalkyne $\operatorname{Pd}(0)$ derivative. The analysis of the kinetic problem by means of the NMR technique, while allowing a solution to the first puzzle, raised a

\footnotetext{
* Corresponding author.

E-mail address: cano@unive.it (L. Canovese).
}

further chemical question [1]. As a matter of fact, these complexes, when reacting with dimethylacetylene dicarboxylate (DMA) under NMR experimental conditions $\left(T=298 \mathrm{~K},[\right.$ complex $] \approx 1 \times 10^{-2} \mathrm{~mol} \mathrm{dm}^{-3}, 0.25<[\mathrm{DMA}] /$ [complex] $<60$ ) beside the main product cyclopalladate gave rise to the formation of the highly symmetric hexamethyl mellitate molecule. Hexamethyl mellitate is synthesized by means of several catalysts based on different metals with yields ranging from $10 \%$ to $65 \%$ [2]. In a few cases, palladium complexes were used [3]. The palladium mediated synthesis of the mellitate in fact requires longer time, high temperature and high alkyne excess [4]. Therefore, we decided to investigate exhaustively the reaction leading to the palladacyclopentadienyl species in the awareness that the formation of hexamethyl mellitate, albeit under unusually mild conditions, only represents an interesting side reaction. Thus, we planned an experimental network in which different complexes and different alkyne/complex ratios were analysed. 


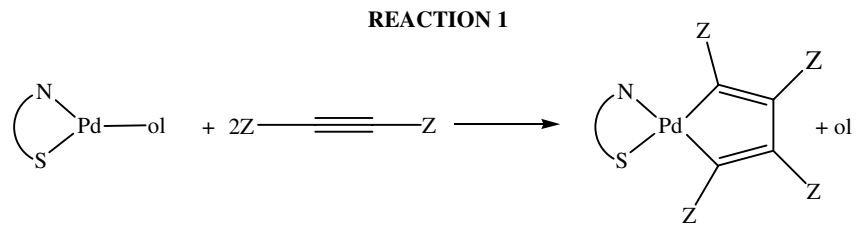

ol = tetramethylethylentetracarboxylate, maleic anhydride $\mathrm{Z}=\mathrm{COOMe}, \mathrm{COOEt}, \mathrm{COO} t$-Bu

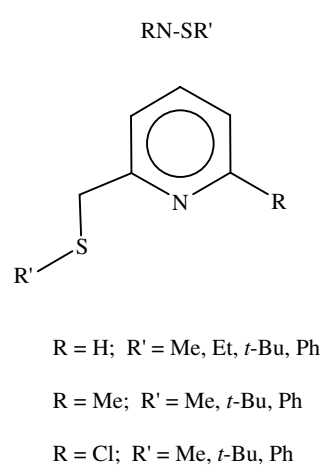

Scheme 1.

The NMR spectra obtained under mild experimental conditions and at low DMA/complex ratios show the formation of the hexamethyl mellitate species as a side product of the main production of cyclopalladate in all the studied cases [5]. Such a symmetric compound was identified from its characteristic singlet at $3.87 \mathrm{ppm}$ in $\mathrm{CDCl}_{3}$, separated after complete precipitation of the cyclometallate complexes from the mother liquor by gas chromatography and characterised by mass spectrometry [6]. The most obvious reaction path involving the attack of a free alkyne molecule to the cyclopalladate was soon ruled out since the isolated cyclopalladate substrate does not react under mild conditions with one further alkyne molecule to give the mellitate. Formation of mellitate requires in fact the presence of the starting complex, free alkyne, and cyclopalladate product. It was soon apparent that mellitate production is not monotonically dependent on the concentration of alkyne. Instead, production of this species passes through a maximum whose position is a function of the alkyne/complex ratio and of the nature of the complex itself, as reported in Fig. 1 and Table 1. It is apparent that: At high alkyne/complex molar ratios the formation of hexamethyl mellitate decreases. This result must be considered general and conclusive and explains why no mellitate is observed under UV/Vis kinetic conditions when the formation of the palladacyclopentadienyl derivative is studied [1]. The highest mellitate production was obtained at different alkyne/complex ratios as a function of the ancillary ligand. The best result for the studied complexes is obtained with $\mathrm{MeN}-\mathrm{SMe}$ as ancillary ligand. The complexes bearing the ligands with the more hindered substituent at sulfur are the less productive substrates.

If we consider the mechanism of formation of palladacyclopentadiene complexes proposed elsewhere [1] and

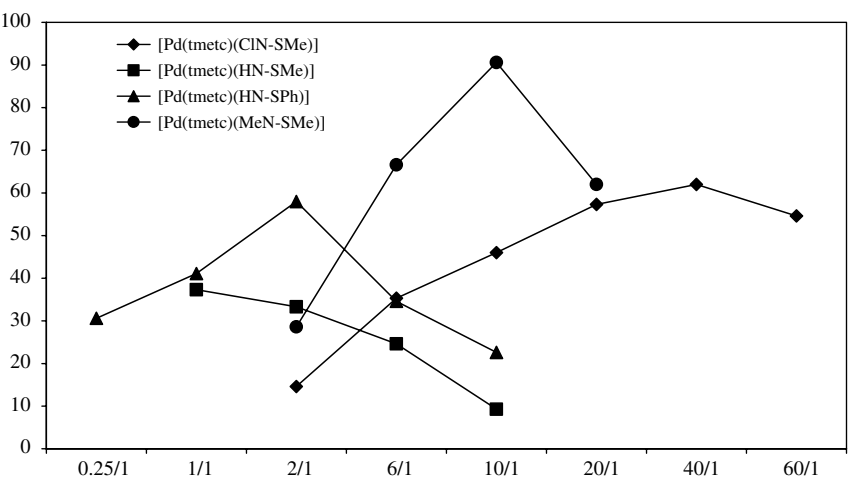

Fig. 1. Concentration profiles of hexamethyl mellitate $(\%$ of starting complex) as a function of alkyne(DMA)/complex molar ratio for the more reactive complexes.

Table 1

Amount of hexamethyl mellitate ( $\%$ of starting complex) as a function of the alkyne(DMA)/complex molar ratio

\begin{tabular}{lllllllll}
\hline$[\mathrm{DMA}] /[$ complex $]$ & $0.25 / 1$ & $1 / 1$ & $2 / 1$ & $6 / 1$ & $10 / 1$ & $20 / 1$ & $40 / 1$ & $60 / 1$ \\
\hline$\left[\mathrm{Pd}\left(\eta^{2}\right.\right.$-tmetc $)$ & & & 14.6 & 35.3 & 46.0 & 57.3 & 62.0 & 54.6 \\
$(\mathrm{ClN}-\mathrm{SMe})]$ & & & & & & & & \\
$\begin{array}{c}{\left[\mathrm{Pd}\left(\eta^{2} \text {-tmetc) }\right.\right.} \\
(\mathrm{HN}-\mathrm{SMe})]\end{array}$ & & 37.3 & 33.3 & 24.6 & 9.3 & & & \\
$\begin{array}{c}\mathrm{Pd}\left(\eta^{2} \text {-tmetc }\right) \\
(\mathrm{HN}-\mathrm{SPh})]\end{array}$ & 30.6 & 41.1 & 58.0 & 34.6 & 22.6 & & & \\
$\begin{array}{c}\mathrm{Pd}\left(\eta^{2} \text {-tmetc }\right) \\
(\mathrm{MeN}-\mathrm{SMe})]\end{array}$ & & & 28.6 & 66.6 & 90.6 & 62.0 & & \\
\hline
\end{tabular}

reported in Scheme 2, of which formation of mellitate can be thought of as a side reaction, we can rationalize these findings by supposing that the mellitate arises from slow reaction of the cyclopalladate main product with the monoalkyne palladium $(0)$ intermediate $[\mathrm{Pd}(\mathrm{DMA})(\mathrm{RN}-$ $\left.\mathrm{SR}^{\prime}\right)$ ] involved in the reaction path, followed by fast recombination of the labile, highly reactive $\left[\mathrm{Pd}\left(\mathrm{RN}-\mathrm{SR}^{\prime}\right)\right]$ species with one further DMA molecule to restore the monoalkyne intermediate complex according to Scheme 3.

In this context, the reactivity of the monoalkyne derivatives 2 undergoing two competitive reactions is probably crucial. As a matter of fact the $\operatorname{Pd}(0)$ complex bearing the

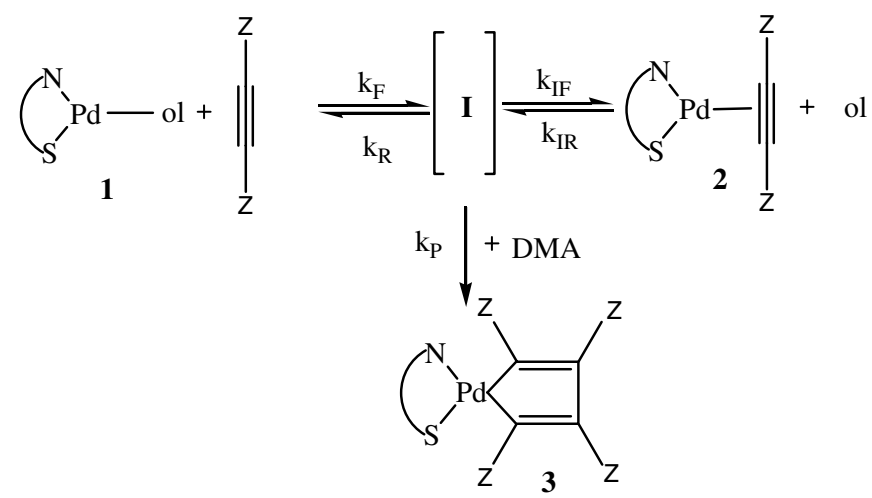

Scheme 2 . 


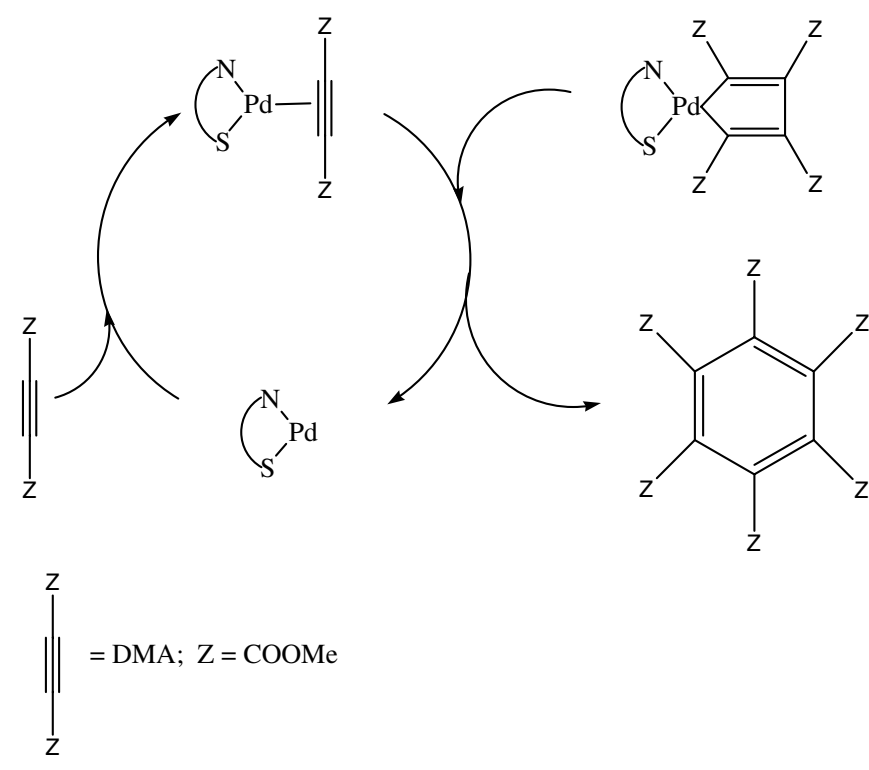

Scheme 3.

hindered ancillary ligand $\mathrm{MeN}-\mathrm{S} t$-Bu gives rise to the formation of the largest quantity of monoalkyne species among all the studied pyridylthioether compounds [1]. Therefore, owing to its reduced reactivity (no accumulation would otherwise be possible) the $\left[\mathrm{Pd}\left(\eta^{2}-\mathrm{ol}\right)(\mathrm{MeN}-\mathrm{S} t-\mathrm{Bu})\right]$ derivative becomes the least effective in producing the hexamethyl mellitate. The maximum of mellitate production probably arises from a delicate balance of the kinetic rate constants (which are strongly influenced by the mutual reactivity) and the actual concentration of all the species involved in Schemes 2 and 3 probably as a result of donor-acceptor properties and steric requirements of the ancillary ligand substituents. Under these circumstances any attempt at resolving analytically the mechanistic network is not warranted owing to the complexity of the mechanistic hypothesis. Schemes 2 and 3, however, represent the most plausible path among all those conceivable for the mellitate production under mild conditions.

\section{References}

[1] L. Canovese, F. Visentin, G. Chessa, P. Uguagliati, C. Levi, A. Dolmella, Organometallics 24 (2005) 5537.

[2] (a) B.K. Campion, R.H. Heyn, T.D. Tilley, Organometallics 9 (1990) 1106

(b) N.D. Feasey, S.A.R. Knox, A.G. Orpen, M.J. Winter, New J. Chem. 12 (1988) 581;

(c) H.L. Aalten, G. van Koten, E. Riethorst, C.H. Stam, Inorg. Chem. 28 (1989) 4140;

(d) D.M. Macomber, A.G. Verma, R.D. Rogers, Organometallics 7 (1988) 1241

(e) U. Koelle, B. Fuss, Chem. Ber. 119 (1986) 116;

(f) U. Kruerke, W. Huebel, Chem. Ber. 94 (1961) 2829;

(g) A. Funhoff, H. Schaeufele, U. Zenneck, J. Organomet. Chem. 345 (1988) 331;

(h) R.S. Dickson, G.S. Evans, G.D. Fallon, Aust. J. Chem. 38 (1985) 273;

(i) M.I. Bruce, A. Catlow, M.G. Humphrey, G.A. Koutsantonis, M.R Snow, E.R.T. Tiekink, J. Organomet. Chem. 338 (1988) 59.

[3] H. tom Dieck, C. Munz, C. Müller, J. Organomet. Chem. 384 (1990) 243.

[4] K. Mosely, P.M. Maitlis, J. Chem. Soc., Dalton Trans. (1974) 169.

[5] NMR spectra were taken on a Bruker Avance 300 spectrometer using $\mathrm{CDCl}_{3}$ as solvent which was used as purchased.

[6] Acetone and $\mathrm{CH}_{2} \mathrm{Cl}_{2}$ were distilled under inert atmosphere (Ar) on $\mathrm{CaH}_{2}$ or molecular sieves (4A), respectively. $\mathrm{CHCl}_{3}$ was distilled under $\mathrm{Ar}$ and stored on silver leaf. Gas-mass analyses were performed with a Trace GC 2000 connected to a Finnigan Trace MS, using a $30 \mathrm{~m}$, $0.25 \mathrm{~mm}$ ID, Rtx-5MS capillary column (5:95 diphenyl-/dimethylpolysiloxane). 